\title{
Comunicação
}

\section{Manga 'Ubá' tratada com ethephon na pré-colheita}

\author{
Danielle Fabíola Pereira da Silva ${ }^{1}$, Luiz Carlos Chamhum Salomão², Dalmo Lopes de Siqueira², \\ Paulo Roberto Cecon ${ }^{2}$, Aline Rocha ${ }^{3}$
}

\section{RESUMO}

A manga 'Ubá' amadurece, geralmente, de novembro a janeiro, e a maturação desuniforme em uma mesma planta exige colheita escalonada, que pode prolongar-se por até um mês. Foram avaliados os efeitos de diferentes concentrações de ethephon na antecipação e na uniformização do amadurecimento e nos atributos de qualidade da manga 'Ubá'. Na 17 ${ }^{\text {a }}$ semana após a antese, 25 mangueiras, sendo cinco por tratamento, foram pulverizadas com ethephon, nas concentrações de $0,250,500,750$ e $1000 \mathrm{mg} \mathrm{L}^{-1}$, acrescido de $0,5 \%$ de óleo mineral. Foram colhidos cinco frutos de cada planta, diariamente, até o completo amadurecimento, com exceção da dose $0 \mathrm{mg} \mathrm{L}^{-1}$, em que, a partir de seis dias após aplicação do ethephon (DAAE), a colheita foi semanal, até 41 DAAE. Os frutos colhidos foram armazenados a 20,0 \pm $0,8{ }^{\circ} \mathrm{C}$ e a $90 \pm 5 \%$ de umidade relativa e avaliados após o completo amadurecimento. A aplicação do ethephon em précolheita antecipou a colheita de manga 'Ubá' em até 36 dias, uniformizou o amadurecimento dos frutos na planta e dispensou a climatização em pós-colheita. Após a aplicação do ethephon, quanto mais tardia a colheita, mais rapidamente completou-se o amadurecimento e melhor foi a qualidade final do fruto. A concentração de $750 \mathrm{mg} \mathrm{L}^{-1}$ de ethephon, seguida da colheita três dias depois, foi a que proporcionou frutos de melhor qualidade.

Palavras-chave: Mangifera indica L., etileno, amadurecimento.

\section{ABSTRACT}

\section{'Ubá' mango treated with ethephon at preharvest}

The 'Uba' mango generally ripens from November to January, and ripening in the same plant is uneven, requiring selective harvest, which may extend up to a month. We evaluated the effects of different concentrations of ethephon in promoting early uniform ripening and quality attributes of 'Ubá' mango. In the $17^{\text {th }}$ week after anthesis, 25 mango trees, five per treatment, were sprayed with ethephon at concentrations of $0,250,500,750$ and $1000 \mathrm{mg} \mathrm{L}^{-1} \mathrm{plus}_{0.5 \%}$ of mineral oil. Five fruits were collected from each plant daily until complete ripening, except for the concentration $0 \mathrm{mg} \mathrm{L}^{-}$ ${ }^{1}$, at which, from 6 days after ethephon application (DAEA), fruits were harvested weekly until 41 DAEA. After harvest, the fruits were stored at $20.0 \pm 0.8$ and $90{ }^{\circ} \mathrm{C} \pm 5 \% \mathrm{RH}$ and evaluated after complete ripening. The preharvest application of ethephon advanced harvest of 'Ubá' mango by about 36 days, promoted uniform ripening of fruits on the plant and eliminated the need of ethylene application in the postharvest. After the ethephon application, the more delayed the harvesting, the more quickly the ripening takes place and the better the final quality of the fruit. The concentration of $750 \mathrm{mg} \mathrm{L}^{-1}$ ethephon, and harvesting three days post-application, resulted in better fruit quality.

Key words: Mangifera indica L., ethrel, postharvest.

\footnotetext{
Recebido para publicação em 04/10/2011 e aprovado em 12/04/2012

${ }^{1}$ Engenheira-Agrônoma, Doutora. Pós-Doutoranda do Departamento de Fitotecnia, Universidade Federal de Viçosa, Campus Viçosa, Avenida Peter Henry Rolfs, s/n, 36570-000, Viçosa, Minas Gerais, Brasil. danieele @ufv.br (autora para correspondência)

${ }^{2}$ Engenheiro-Agrônomo, Doutor. Departamento de Fitotecnia, Universidade Federal de Viçosa, Campus Viçosa, Avenida Peter Henry Rolfs, s/n, 36570-000, Viçosa, Minas Gerais, Brasil.1salomao@ufv.br; siqueira@ufv.br; cecon@ufv.br

${ }^{3}$ Engenheira-Agrônoma, Doutora. Instituto Federal de Educação, Ciência e Tecnologia do Sertão Pernambucano, Rodovia BR 235, Km 22, Projeto Senador Nilo Coelho, 04, 56300-000, Petrolina, Pernambuco, Brasil. rochaline@ @otmail.com
} 


\section{INTRODUÇÃO}

O etileno está diretamente relacionado com o processo de amadurecimento dos frutos. Por isso, frutos fisiologicamente maduros de diversas espécies são tratados com este regulador de crescimento e,ou, seus análogos sintéticos, visando a acelerar e uniformizar o amadurecimento e,ou, melhorar o padrão de qualidade. Com esses fins, entretanto, o uso do etileno tem-se restringido principalmente à pós-colheita de frutos.

Por causa da alta taxa de difusão, é difícil aplicar etileno no campo sob a forma de gás, mas tal limitação pode ser superada, utilizando um composto que libere etileno (Brackmann et al., 2007), como o ácido 2-cloroetilfosfônico (ethephon). Em pH igual ou superior a 5, ocorre hidrólise do ácido e liberação de etileno (Steffens \& Brackmann, 2006).

O ethephon tem eficiência na antecipação e uniformização da mudança de coloração da casca de vários frutos não climatéricos e no amadurecimento de frutos climatéricos, quando utilizado na pós-colheita, como por exemplo, de banana (Salomão \& Maia, 2004), frutos cítricos (Domingues et al., 2001), maçã (Steffens \& Brackmann, 2006), ameixa (Fioravanço et al., 2007), tomate (Andreuccetti et al., 2007), pêra (Lombardi et al., 2000) e manga (Braz et al., 2008; Aguila et al., 2011) . Entretanto, não há registro no Ministério da Agricultura, Pecuária e Abastecimento para uso de ethephon na pós-colheita de frutas (Agrofit, 2010).

Na pré-colheita, ou seja, para aplicação no campo, há registro do ethephon, em suas várias formulações comerciais, para uso em diversas culturas e com várias finalidades. Para a manga, há o registro para indução do florescimento (Agrofit, 2010).

$\mathrm{O}$ uso deste produto em pré-colheita foi testado em pêssegos 'Eldorado' (Brackmann et al., 2007) e em peras 'Packham's Triumph' (Seibert et al., 2000), confirmando o seu potencial para antecipar o amadurecimento dos frutos.

Não foram encontrados, na literatura consultada, relatos de uso de ethephon na pré-colheita de manga 'Ubá'. A possibilidade de ser efetivo em uniformizar e antecipar a colheita da manga 'Ubá' traria vantagem para o produtor, ao proceder a colheita de todos os frutos da planta de uma só vez. Para a indústria de polpa e suco, o uso do produto permitiria o escalonamento da oferta e, consequentemente, a otimização do uso de máquinas e mão de obra para beneficiar o fruto.

A partir desse contexto, o objetivo do trabalho foi avaliar os efeitos de diferentes doses de ethephon, na antecipação e uniformização da colheita e nos atributos de qualidade de frutos de mangueira 'Ubá'.

\section{MATERIAL E MÉTODOS}

O experimento foi conduzido em pomar de mangueiras 'Ubá' (Mangifera indica L.), com aproximadamente 30 anos de idade, pertencente à Universidade Federal de Viçosa, localizado em Visconde do Rio Branco, MG, Brasil ( $21^{\circ} 00^{\prime} 37^{\prime \prime} \mathrm{LS}, 42^{\circ} 50^{\prime} 26^{\prime \prime} \mathrm{LO}$, altitude de $352 \mathrm{~m}$ ).

No dia 2 de dezembro de 2007, que correspondeu à $17^{\text {a }}$ semana após a antese (quando os frutos encontravam-se fisiologicamente maduros), as plantas foram pulverizadas com ácido 2-cloroetilfosfônico (produto comercial Ethrel, 240 g i.a./L), nas concentrações de 0, 250, 500, 750 e 1000 $\mathrm{mg} \mathrm{L}^{-1}$, acrescido de $0,5 \mathrm{~mL} \mathrm{~L}^{-1}$ de óleo mineral (produto comercial ASSIST). Foram colhidos cinco frutos de cada mangueira nos dias $(0,1,2,3,4,5,6,14,21,28,35$ e 41), até o completo amadurecimento na planta, sendo que, para a dose $0 \mathrm{mg} \mathrm{L}^{-1}$, seis dias após a aplicação do ethephon (DAAE), a colheita foi realizada semanalmente, até 41 DAAE. Após a colheita, foram lavados, imersos em solução de fungicida Prochloraz (49,5 mL/100 L de água) por cinco minutos, secos ao ar ambiente, armazenados a 20,0 $\pm 0,8{ }^{\circ} \mathrm{C}$ e a $90 \pm 5 \%$ de umidade relativa e avaliados após o completo amadurecimento. Os frutos foram considerados maduros quando apresentaram coloração da casca totalmente amarela de acordo com escala de cor visual (Braz et al., 2008).

Os frutos foram avaliados quanto à coloração da polpa, determinada pela leitura das coordenadas $\mathrm{L}^{*}, \mathrm{a}^{*} \mathrm{e} \mathrm{b}^{*}$ na região central de cada fruto, próximo ao caroço, com um colorímetro (Color Reader CR-10 Minolta) e os resultados foram expressos pelo ângulo hue (ângulo de cor h) $\left(0^{\circ}=\right.$ vermelho; $90^{\circ}=$ amarelo; $180^{\circ}=$ verde $; 270^{\circ}=$ azul $)$ e pela diferença de cor da polpa $(\Delta \mathrm{E})$, a qual é calculada pela fórmula $\Delta \mathrm{E}=\left(\Delta \mathrm{L}^{* 2}+\Delta \mathrm{a}^{* 2}+\Delta \mathrm{b}^{* 2}\right)^{0,5}$. O $\Delta \mathrm{E}$ foi calculado nos diversos intervalos de tempo, sempre em relação aos valores obtidos no dia zero (antes da aplicação de ethephon), para cada tratamento (Minolta Corp, 1994).

A consistência da polpa $(\mathrm{kPa})$ foi determinada com penetrômetro digital Shimpo modelo DFS 100, dotado de ponteira de $12 \mathrm{~mm}$ de diâmetro; o teor de sólidos solúveis (SS - ${ }^{\circ}$ Brix) foi determinado por refratometria e, a acidez titulável (AT) da polpa, por titulação com $\mathrm{NaOH} 0,1 \mathrm{~N}$, de acordo com as normas analíticas do Instituto Adolfo Lutz (2005), expressa em percentagem de ácido cítrico. Além disto, também foi determinada a razão SS/AT.

$\mathrm{O}$ delineamento experimental foi o inteiramente casualizado, em esquema de parcelas subdivididas, alocando-se, nas parcelas, as cinco doses de ethephon, e, nas subparcelas, os dias de avaliação, com cinco repetições de uma mangueira cada e cinco frutos por unidade experimental. Os dados foram analisados por meio das análises de variância e regressão. Os modelos, ajustados por meio de regressão, foram escolhidos com base na significância dos coeficientes de regressão, a cinco por cento de probabilidade, pelo teste "t", de Student, no coeficiente de determinação e no potencial para explicar o fenômeno biológico. O programa estatístico utilizado foi 
o Sistema de Análises Estatísticas e Genéticas da Universidade Federal de Viçosa, versão 9.1 (SAEG, 2007).

\section{RESULTADOS E DISCUSSÃO}

Para frutos colhidos em cada um dos dias subsequentes à aplicação de ethephon, não se observou efeito das doses para a característica diferença de cor da polpa $(\Delta \mathrm{E}$, Figura 1A). Entretanto, quanto mais tardiamente os frutos foram colhidos, maiores foram os valores médios de $\Delta \mathrm{E}$, indicando que a maior permanência do fruto na planta e, consequentemente, o aumento do período em contato com o etileno, mais se intensificou a coloração final da polpa. De acordo com Salomão \& Maia (2004), as modificações na coloração das frutas, com o avanço do amadurecimento, ocorrem por causa dos processos degradativos ou sintéticos, sendo utilizadas como critério de julgamento do amadurecimento de frutas.

Para os frutos colhidos nos dias ( $0,1,4$ e 5) após a aplicação de ethephon, o ângulo hue para coloração da polpa não se alterou com o aumento das doses do produto (Figura 1B). Para os frutos colhidos no 2o e 3o DAAE, ajustaram-se modelos quadráticos, com valores mínimos de $\mathrm{h}$ entre as doses de 500 e $750 \mathrm{mg} \mathrm{L}^{-1}$. Por outro lado, observou-se que, em geral, quanto mais tardia foi a colheita, menor foi o valor do $\mathrm{h}$, indicando que a maior permanência do fruto na planta após a aplicação do ethephon contribui para que este adquira coloração mais amarela ou alaranjada, o que é essencial para a indústria e para o consumo 'in natura'.

Não se observou efeito de doses de ethephon na consistência da polpa, independentemente do dia de colheita. Observou-se, contudo, que, quanto mais se retardou a colheita dos frutos, menor foi a consistência apresentada após o completo amadurecimento (Figura 1C), os ajustes em forma de constante indicam a ausência de efeito de dose. Contudo, a redução dos valores médios, do 0 ao $5^{\circ}$. DAAE, indicam que retardar a colheita torna o fruto mais macio após o amadurecimento completo. Portanto, retardar demasiadamente a colheita após a pulverização com ethephon pode reduzir o período de comercialização do fruto, por torná-lo mais sensível a danos mecânicos. Brackmann et al. (2007) também observaram que, em pêssego 'Eldorado', tratados com ethephon na pré-colheita, a consistência da polpa foi significativamente menor. Seibert et al. (2000), trabalhando com peras 'Packham's Triumph', tratadas em pré-colheita com $0 ; 12,5 ; 25 ; 50$ e $100 \mathrm{mg} \mathrm{L}^{-1}$ de ethephon, observaram que quanto maior a dose de ethephon menor foi a firmeza dos frutos.

Nos frutos colhidos nos dias (0, 1 e 2) após a aplicação de ethephon, o teor de sólidos solúveis não foi alterado pelas doses de ethephon (Figura 1D). Nos três casos, o teor de sólidos solúveis atingido ao final do amadureci- mento foi baixo, variando de 13,49 a $16,25^{\circ}$ brix. Para as coletas dos dias ( 3 , 4 e 5), o efeito foi quadrático, com teor de sólidos solúveis máximo entre as doses de 500 e 750 $\mathrm{mg} \mathrm{L}^{-1}$. Para frutos colhidos nos 3 e 4 DAAE, o teor de sólidos solúveis superou $18^{\circ}$ Brix nas doses de 500,750 e $1000 \mathrm{mg} \mathrm{L}^{-1}$. Para frutos colhidos no 5-DAAE, o teor de sólidos solúveis superou $18{ }^{\circ}$ Brix para todas as doses, com exceção de $0 \mathrm{mg} \mathrm{L}^{-1}$.

De forma mais limitada em relação à extensão do período de safra, o ethephon foi utilizado na pós-colheita da manga 'Keitt' e frutos tratados com $1.000 \mathrm{mg} \mathrm{L}^{-1}$ de ethrel tiveram o seu amadurecimento antecipado, em relação aos frutos controle (Coneglian \& Rodrigues, 1993).

A acidez titulável não foi influenciada pelas doses de ethephon, nas coletas dos dias ( $0,1,2,3$ e 4$)$, sendo que, quanto mais tardiamente foram colhidos, menor foi a acidez titulável. Por outro lado, os frutos colhidos no $5^{\circ}$. DAAE apresentaram menor acidez titulável entre as doses de $500 \mathrm{e}^{2} 750 \mathrm{mg} \mathrm{L}^{-1}$ (Figura 1E), mais uma vez evidenciando a efetividade dessas doses na promoção do amadurecimento. De acordo com Salomão \& Maia (2004), o decréscimo do ácido contido em grande quantidade em mangas verdes dá-se de modo muito lento, podendo ocorrer prejuízos no momento da colheita, já que, em alguns casos, o fruto apresenta-se completamente amarelado, porém ainda com polpa ácida. Portanto, as doses de 500 e $750 \mathrm{mg} \mathrm{L}^{-1}$ foram mais efetivas em promover o completo amadurecimento dos frutos.

A relação entre ${ }^{\circ}$ Brix e acidez titulável (Figura 1F) apresentou comportamento semelhante ao dos sólidos solúveis (Figura 1D). A maior relação SS/AT foi observada nos frutos completamente maduros da colheita do dia 5, visto que, para este dia, os frutos apresentaram o maior teor de sólidos solúveis (Figura 1D) e menor acidez titulável (Figura 1E), sendo as doses de 500 a $750 \mathrm{mg} \mathrm{L}^{-1}$ de ethephon as que proporcionaram maior relação SS/AT.

Também nota-se que, quanto mais se retardou a colheita, menor foi o tempo necessário para que os frutos completassem o amadurecimento, independentemente da dose (Tabela 1). Neste sentindo, a dose de $750 \mathrm{mg} \mathrm{L}^{-1}$ foi a que se mostrou mais efetiva em acelerar o amadurecimento, antecipando-o em 36 dias, em comparação com a dose $0 \mathrm{mg} \mathrm{L}^{-1}$. Frutos colhidos no 3 - DAAE (05/12/2007) atingiram o completo amadurecimento, após 12, 7, 6, 4 e 6 dias para as doses de $0,250,500,750 \mathrm{e} 1000 \mathrm{mg} \mathrm{L}^{-1}$, respectivamente. Considerando-se a dose de $750 \mathrm{mg} \mathrm{L}^{-1}$, o amadurecimento em quatro dias corresponde ao mesmo tempo despendido quando o tratamento com ethephon, carbureto de cálcio ou etileno ocorre na pós-colheita dos frutos. Portanto, torna-se evidente que o ethephon aplicado em pré-colheita também dispensa a aplicação tradicional feita na pós-colheita. Esse procedimento, pela precariedade 
com que é geralmente executado, é das principais causa de perdas da fruta. Os frutos tratados com $1000 \mathrm{mg} \mathrm{L}^{-1}$ demoraram mais tempo para amadurecer e apresentaram menor teor de sólidos solúveis e maior acidez titulável, que aqueles pulverizados com $750 \mathrm{mg} \mathrm{L}^{-1}$. Além disso, houve queda de folhas das plantas. Isso sugere efeito negativo do etileno aplicado em elevada concentração, sobre o amadurecimento da manga 'Ubá'.

A avaliação do conjunto dos resultados permite indicar a aplicação da dose de $750 \mathrm{mg} \mathrm{L}^{-1}$, seguido da
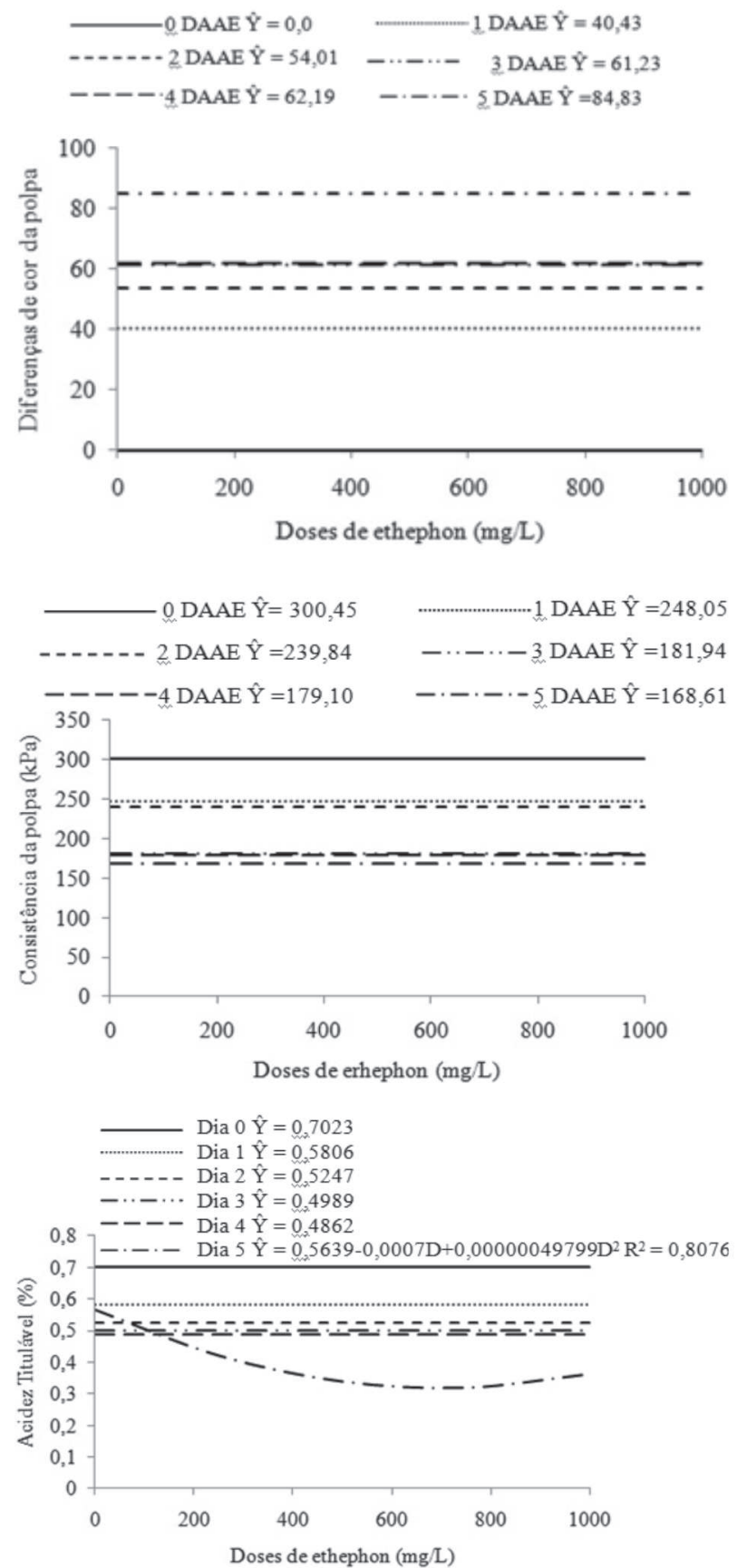

colheita dos frutos três dias após aplicação do ethephon. Procedendo-se dessa forma, não se observou abscisão de folhas ou frutos, ou qualquer outro sintoma depreciativo nas mangueiras. Por outro lado, observou-se a antecipação e a uniformização do amadurecimento dos frutos, possibilitando uma única colheita por planta. Também foi observado que os frutos adquiriram, ao completar o amadurecimento, características físicas e químicas semelhantes às daqueles amadurecidos naturalmente na planta. Ao ser gerado
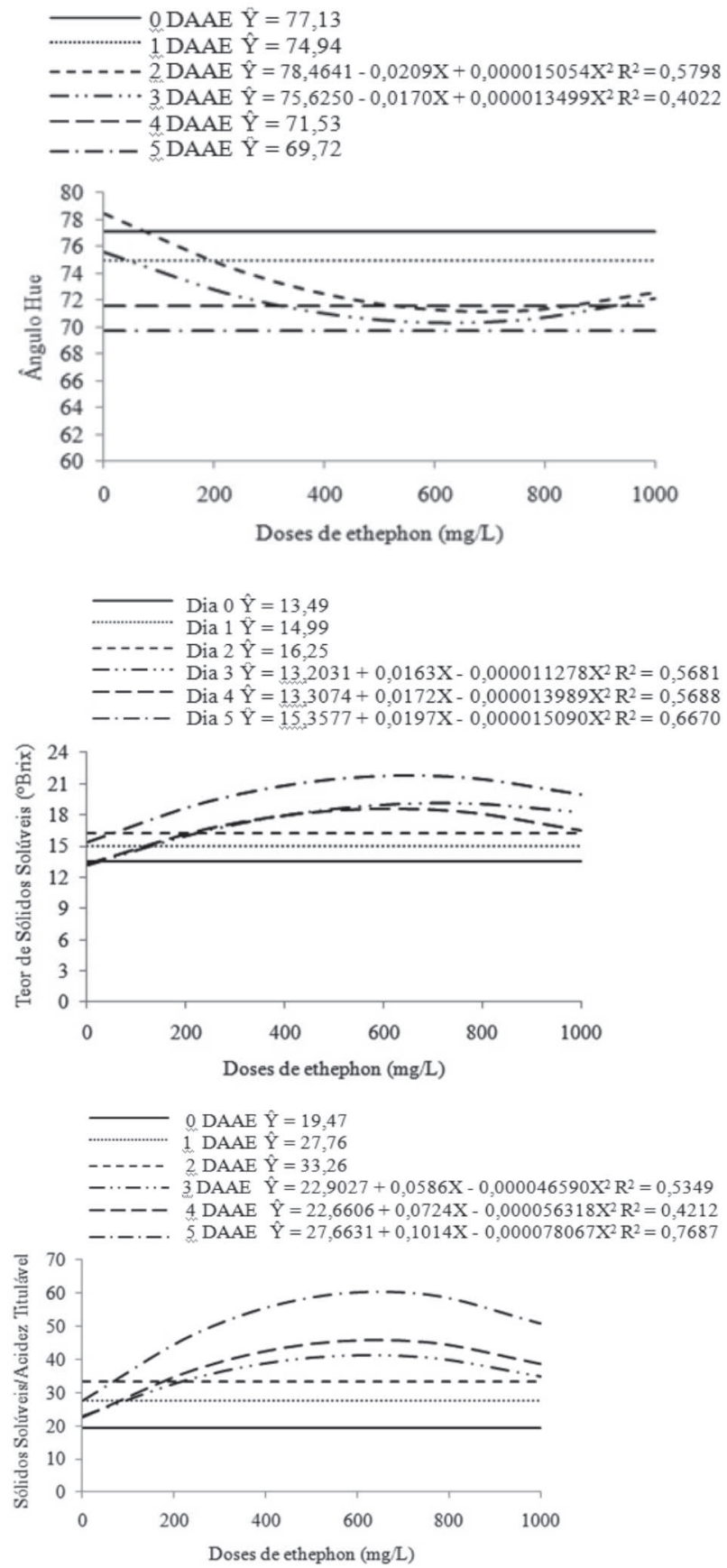

Figura 1. Diferença de cor da polpa da manga 'Ubá' em relação à cor no dia da aplicação do ethephon (A), ângulo hue (B), consistência da polpa (C), teor de sólidos solúveis (D), acidez titulável (E) e relação teor sólidos solúveis/ acidez titulável (F) da manga 'Ubá' em frutos colhidos nos dias subsequentes à aplicação de ethephon e analisados após o amadurecimento completo. DAAE: dias após a aplicação de ethephon.

Rev. Ceres, Viçosa, v. 59, n.4, p. 555-559, jul/ago, 2012 
Tabela 1. Tempo (dias) necessário para que frutos tratados ou não tratados com ethephon atingissem o completo amadurecimento após a colheita

\begin{tabular}{|c|c|c|c|c|c|c|}
\hline \multirow{2}{*}{ Colheita } & \multirow{2}{*}{ DAAE ${ }^{2}$} & \multicolumn{5}{|c|}{ Doses de ethephon $\left(\mathrm{mg} \mathrm{L}^{-1}\right)$} \\
\hline & & $\mathbf{0}$ & 250 & 500 & 750 & 1000 \\
\hline $02 / 12 / 2007^{1}$ & 0 & 12 & - & - & - & - \\
\hline 03/12/2007 & 1 & 12 & 8 & 7 & 5 & 8 \\
\hline 04/12/2007 & 2 & 12 & 8 & 7 & 4 & 7 \\
\hline 05/12/2007 & 3 & 12 & 7 & 6 & 4 & 6 \\
\hline 06/12/2007 & 4 & 12 & 5 & 5 & 3 & 5 \\
\hline 07/12/2007 & 5 & 11 & 5 & 4 & 2 & 4 \\
\hline 08/12/2007 & 6 & 11 & - & - & - & - \\
\hline $13 / 12 / 2007$ & 14 & 11 & - & - & - & - \\
\hline $18 / 12 / 2007$ & 21 & 6 & - & - & - & - \\
\hline $27 / 12 / 2007$ & 28 & 5 & - & - & - & - \\
\hline 03/01/2008 & 35 & 3 & - & - & - & - \\
\hline 10/01/2008 & 42 & 0 & - & - & - & - \\
\hline
\end{tabular}

${ }^{1}$ Data da pulverização com ethephon, correspondente à 17 semana após a antese. ${ }^{2}$ Dias após a aplicação de ethephon.

no interior dos tecidos, o etileno, aparentemente, induziu a formação de camada de abscisão, facilitando o procedimento da colheita da manga. Para mangas destinadas à indústria, muito tempo pode ser economizado na operação de colheita, feita geralmente pela agitação dos ramos da árvore.

\section{CONCLUSÕES}

O uso do ethephon em pré-colheita antecipa a colheita de manga 'Ubá' em até 36 dias, sincroniza o amadurecimento dos frutos na planta e dispensa a climatização em pós-colheita. Após a aplicação do ethephon, quanto mais tardia a colheita, mais rapidamente completa-se o amadurecimento e melhor é a qualidade final do fruto. A aplicação de $750 \mathrm{mg} \mathrm{L}^{-1}$ de ethephon em pré-colheita, seguida da colheita três dias depois, é a que proporcionou frutos de melhor qualidade.

\section{AGRADECIMENTOS}

À CAPES, ao CNPq e à FAPEMIG, pelo apoio financeiro.

\section{REFERÊNCIAS}

Aguila JS del, Ortega EMM, Aguila LSH-del \& Kluge RA (2011) Efeito de diferentes temperaturas de aplicação ou não de etileno exógeno sobre a qualidade da manga 'Tommy Atkins'. Revista Brasileira de Fruticultura, 33:298-305.

Agrofit (2010) Sistema de agrotóxicos fitossanitários. Disponível em: <http://agrofit.agricultura.gov.br/ agrofit_cons/ principal_agrofit_cons>. Acessado em: 21 de março de 2011.

Andreuccetti C, Ferreira MD, Moretti CL \& Honório SL (2007) Qualidade pós-colheita de frutos de tomate cv. Andréa tratados com etileno. Horticultura Brasileira, 25:122-126.

Brackmann A, Giehl RFH, Sestari I, Pinto JAV \& Eisermann AC (2007) Qualidade de pêssegos cv. 'Eldorado' tratados com aminoetoxivinilglicina e ethephon e armazenados em atmosfera controlada. Ciência Rural, 37:79-84.
Braz VB, Nunes ES, Vieira G, Ribeiro JI, Bertini LA \& Couto FA (2008) Indução do amadurecimento de mangas cv. Tommy Atkins e cv. Ubá pela aplicação de ethepon pós-colheita. Bragantia, 67:225-232.

Coneglian RCC \& Rodrigues JD (1993) Efeito da aplicação de etileno no $\mathrm{pH}$, acidez, índice refratométrico e açúcares totais de frutos de manga, colhidos em estágio pré-climatérico. Scientia Agricola, 50:185-192.

Domingues MCS, Ono EO \& Rodrigues JD (2001) Indução do amadurecimento de frutos cítricos em pós-colheita com a aplicação de ethephon. Revista Brasileira de Fruticultura, 23:555558 .

Fioravanço JC, Paiva MC \& Bizzani E (2007) Ethephon na antecipação da colheita e qualidade da ameixa cv. Reubennel. Scientia Agraria, 8:193-197.

Instituto Adolfo Lutz (2005) Normas analíticas do Instituto Adolfo Lutz. Métodos físico-químicos para análise de alimentos, $4^{\mathrm{a}}$ ed. Brasília. 1018p.

Lombardi SRB, Moraes DM de \& Camelatto D (2000) Avaliação do crescimento e da maturação pós-colheita de pêras da cultivar Shinsseiki. Pesquisa Agropecuária Brasileira, 35:2399-2405.

Minolta Corp (1994) Precise color communication: color control from feeling to instrumentation. Ramsey, Minolta Corporation Instrument Systems Division. 49p.

Sistema para Análises Estatísticas - SAEG (2007) versão 9.1. Viçosa, Fundação Arthur Bernardes, UFV. CD ROM.

Salomão LCC \& Maia VM (2004) Amadurecimento de quatro cultivares de banana com ácido 2-cloroetilfosfônico. Revista Brasileira de Armazenamento, 29:104-113.

Seibert E, Barradas CIN, Araújo PJ de \& Bender RJ (2000) Efeito do ethephon e da frigoconservação na maturação de Peras cv. 'Packham's Triumph'. Pesquisa Agropecuária Brasileira, 35:5562.

Steffens CA \& Brackmann A (2006) Maturação da maçã 'Fuji' com aplicação pré-colheita de aminoetoxivinilglicina e ethephon. Revista da Revista da Faculdade de Zootecnia, Veterinária e Agronomia- FZVA, 13:76-84.

Rev. Ceres, Viçosa, v. 59, n.4, p. 555-559, jul/ago, 2012 